\title{
Circuit World
}

\section{Emerald Article: Influences on the reflow soldering process by components with specific thermal properties \\ Florian Schüßler, Denis Kozic, Jörg Franke}

\section{Article information:}

To cite this document: Florian Schüßler, Denis Kozic, Jörg Franke, (2009),"Influences on the reflow soldering process by components with specific thermal properties", Circuit World, Vol. 35 Iss: 3 pp. 35 - 42

Permanent link to this document: http://dx.doi.org/10.1108/03056120910979530

Downloaded on: 28-01-2013

References: This document contains references to 6 other documents

Citations: This document has been cited by 2 other documents

To copy this document: permissions@emeraldinsight.com

This document has been downloaded 227 times since 2009. *

\section{Users who downloaded this Article also downloaded: *}

Florian Schüßler, Denis Kozic, Jörg Franke, (2009),"Influences on the reflow soldering process by components with specific thermal properties", Circuit World, Vol. 35 Iss: 3 pp. 35 - 42

http://dx.doi.org/10.1108/03056120910979530

Florian Schüßler, Denis Kozic, Jörg Franke, (2009),"Influences on the reflow soldering process by components with specific thermal properties", Circuit World, Vol. 35 Iss: 3 pp. 35 - 42

http://dx.doi.org/10.1108/03056120910979530

Florian Schüßler, Denis Kozic, Jörg Franke, (2009),"Influences on the reflow soldering process by components with specific thermal properties", Circuit World, Vol. 35 Iss: 3 pp. 35 - 42

http://dx.doi.org/10.1108/03056120910979530

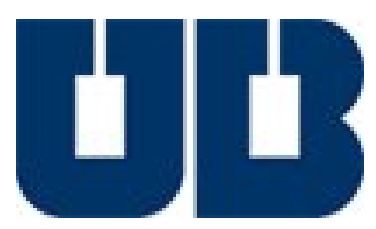

Access to this document was granted through an Emerald subscription provided by FRIEDRICH ALEXANDER UNIVERSITAET ERLANGE NUERNBERG

For Authors:

If you would like to write for this, or any other Emerald publication, then please use our Emerald for Authors service. Information about how to choose which publication to write for and submission guidelines are available for all. Please visit www.emeraldinsight.com/authors for more information.

\section{About Emerald www.emeraldinsight.com}

With over forty years' experience, Emerald Group Publishing is a leading independent publisher of global research with impact in business, society, public policy and education. In total, Emerald publishes over 275 journals and more than 130 book series, as well as an extensive range of online products and services. Emerald is both COUNTER 3 and TRANSFER compliant. The organization is a partner of the Committee on Publication Ethics (COPE) and also works with Portico and the LOCKSS initiative for digital archive preservation. 


\title{
Influences on the reflow soldering process by components with specific thermal properties
}

\author{
Florian Schüßler, Denis Kozic and Förg Franke \\ Institute for Manufacturing Automation and Production Systems (FAPS), University of Erlangen-Nuremberg, Erlangen, Germany
}

\begin{abstract}
Purpose - The purpose of the paper is to focus on the research into components with specific thermal properties and their influences on the reflow soldering process.

Design/methodology/approach - After a brief introduction, the paper gives an overview of the necessity of thermal management on printed circuit boards (PCBs) and the possible effects on the manufacturing of electronic devices. In the next sections, different test boards are presented for investigations into different thermal effects during soldering. The last section deals with the influences of molded interconnected devices (MIDs) on the reflow soldering process.

Findings - The investigations show that components from the thermal management influence the reflow soldering process more or less. The highest impacts on the soldering process are from components with a thermal connection to the electrical component and its solder joint. All results from the investigations have in common that the thermal influence can only be compensated by increasing the temperature during soldering. However, this significantly increases the risk of overheating the electrical components or the PCB itself.

Research limitations/implications - This paper shows only the influence of some of the effects caused by thermal management on the reflow soldering process. Furthermore, vapour phase soldering is not considered, but actual investigations are carried out on vapour phase soldering ovens as well.

Originality/value - Thermal management becomes more and more important with the increasing functionality of electrical components and electronic devices. This topic has been the subject of a large number of articles. However, this paper deals with influences that thermal management has on the soldering process during the manufacturing of the electronic device.
\end{abstract}

Keywords Electrical components, Thermal efficiency, Soldering, Microvias, Thermal properties of materials

Paper type Research paper

\section{Introduction}

The electronics production nowadays is affected by a multitude of trends of which the miniaturisation of electronic devices and the increasing functionality of electrical components are the only two to be named. Another determinant trend is the increasing thermal loads on printed circuit boards (PCBs). Jointly responsible for the thermal loads are, on the one hand, the dissipation losses of the highly integrated ICs and, on the other hand, the often narrow installation spaces (Ohadi and Qi, 2004). Both are accompanied by the surrounding temperature of the electronic device (Schüßler et al., 2008). To prevent single electrical components from overheating or to reduce the heating up of the surroundings of the whole electrical device, thermal management can be integrated in the PCB.

Components for thermal management usually have a good thermal conductivity or a high thermal mass, respectively, but are influencing the soldering process as well. To get information about those effects, three test boards under different aspects of thermal management were designed and

The current issue and full text archive of this journal is available at www.emeraldinsight.com/0305-6120.htm

Circuit World

35/3 (2009) 35-42

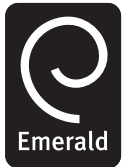

(C) Emerald Group Publishing Limited [ISSN 0305-6120]

[DOI 10.1108/03056120910979530] experiments conducted. In addition, the influences of molded interconnected devices (MIDs) on the soldering process were also investigated. This paper presents and discusses the results of the above-mentioned investigations on those influences.

\section{Thermal management on PCBs}

With the integration of more functions in smaller packages, the heat density is increased in large amounts. The miniaturised design of electronic devices enforces these effects even more. This makes thermal management on PCBs necessary. Hereby, thermal management means the generation and control of heat in electronics circuits. The big challenge for designing the thermal management for an electronic device is that each device will behave differently, depending on the components, the layout and the materials used. The necessity for functional thermal management becomes obvious when considering that with every $10^{\circ} \mathrm{C}$ temperature rise, the rate of chemical reactions doubles. By this, failure mechanisms such as junction failure, metallisation failure and corrosion accelerate (Sergent and Krum, 1998).

The research findings presented in this paper were gathered for the most part within the Collaborative Research Centre 694 "Integration of electronic components in mobile systems" which was established in 2006 at the Friedrich-Alexander-University Erlangen-Nuremberg and is funded by the German Research Foundation (Deutsche Forschungsgemeinschaft - DFG), Friedrich-Alexander-University Erlangen-Nuremberg and the Free State of Bavaria. 
Typical concepts to realise the thermal management on PCBs are given in Feldmann (2008). The cooling of an electrical component can be realised, for example, by spreading the heat into a PCB that has a large area of copper integrated as layers to increase the thermal conductivity. Another principle is the use of thermal vias or the use of rivets to lead the heat from the top side of the PCB to its bottom side where a heat sink can be realised for even better cooling. For very heat critical devices, the board itself can be the heat sink (so-called IMS-Boards) with just a thin electrical isolating layer with the circuitry on it. Heat sinks can also be attached to the top of an electrical component or underneath it.

Besides, the conventional components for a thermal management, thermally conductive thermoplastics are also under investigation (Amesöder et al., 2008). By adding filler materials to the polymers their thermal conductivities can be increased by up to two magnitudes. Theses materials can be used in standard injection moulding processes which gives a considerable freedom in design. Within this process, heat sinks, for example, can be made directly out of thermally conductive thermoplastics or heat-emitting devices can be injection molded with this material, respectively. The fillers are made of electrically conductive metallic materials or electrically isolating ceramics. Depending on the filler material, the filler geometry and the filler content, a thermal conduction with a range of $0.5-20 \mathrm{~W} / \mathrm{mK}$ can be realised (Feldmann, 2008).

Concepts for thermal management that are integrated into the PCB manufacturing process, or that are applied before the processing of the device along the process chain in electronics production have in common that they influence the processes of electronics production. By all means, the soldering process is the most affected. Owing to the higher thermal mass of the PCB with integrated thermal management, the temperature of the soldering profile has to the increased to ensure the satisfactory reflow of the solder paste. This means that components or the PCB itself are exposed to significantly higher temperatures during the soldering process that can lead to damage (Bailey, 2008). In the following, different aspects of the influences of components from the thermal management on the soldering process are investigated.

\section{Thermally linked components}

To protect the electronic devices from overheating, the already mentioned options for thermal management are commonly used. One effective approach for dissipating the generated heat from the component is a thermal connection between the components on the top side of the PCB to the heat sink, typically located on the bottom side. This is often realised using plugged vias, so-called thermal vias, whereby the connection between the surface of the PCB to the thermal pad of the electronic component is realised using a solder joint. Although a higher thermal energy can be dissipated from components with larger cross-sectioned thermal vias, this can result in difficulties during reflow soldering. Since the large thermal mass of the heat sink draws away the energy from the solder during the reflow process, the heat input during soldering has to be increased to be secure that the solder melts during soldering. An increase in the peak temperature in the soldering oven can lead, on the other hand, to an overheating of parts of the PCBs that are not thermally linked to the heat sink. Therefore, the thermal mass of the heat sink and the cross section of the thermal vias have a significant influence on the temperature profiles on PCBs during reflow soldering.

To get information about this influence, a test board was designed that is shown in principle in Figure 1. On this PCB, a total number of nine quad flat packages were connected via thermal pads, a solder joint and thermal vias to a heat sink on the bottom side of the PCB. As can be seen in Figure 1 (bottom) the number, the grid and the cross section of the thermal vias were varied as well as the thermal capacity of the heat sink (made of copper). The size and the material were chosen according to the thermal capacity of a heat sink on the PCB of an electronic stability program control unit $\left(\mathrm{C}_{\mathrm{th}} \approx 54 \mathrm{~J} / \mathrm{K}\right)$. Thermocouples were integrated into each of the nine components to measure the temperature directly in the solder joint.

In the first place, the temperature profile in the soldering oven was designed according to IPC/JEDEC J-STD-020 for the heat sink with a thermal capacity of $25 \mathrm{~J} / \mathrm{K}$. A thermal effect depending on the thermally conductive cross section of the thermal vias can only be seen if the heat conductivity is very limited (Figure 2, for a clear arrangement only three cross sections are shown). Without the connection to a heat sink, an increase in the peak temperature of between 20 and $30 \mathrm{~K}$ on the PCB can be seen for the designed soldering profile. This can lead to specific damage of electrical components due to local overheating or to delamination of the PCB itself. With yet another increase of the thermal capacity of the heat sink, the temperatures at the thermally conducted components decreases significantly. Already from a thermal capacity of $50 \mathrm{~J} / \mathrm{K}$ restrictions in the solderability have to be taken into account.

To counteract these restrictions, it is only possible to increase the temperatures in the zones of the soldering oven, with the risk of an even higher local overheating of components without a thermal connection to the heat sink on the other hand. Another limiting factor is the soldering oven itself, with technological restrictions concerning the maximum temperature that is adjustable. But the experiments showed, as well, that with the use of nitrogen as inert gas, the maximum peak temperature on the PCB can be reduced within the range of $5-10 \mathrm{~K}$. This is because of the better heat transmission of the nitrogen compared to oxygen. Further research will take other inert gases like helium or blends of the named gases for soldering into account as well. With the use of those gases, the maximum temperature could be reduced, even though the reflow of the solder can be secured. This can lead to a lower thermal load on the PCB.

\section{Influence of thermal masses on reflow soldering}

Owing to the need of thermal management, it is necessary to integrate large thermal masses into the design of electronic devices for heat dissipation reasons. With higher integration levels on the one hand and the need for miniaturisation on the other hand, electric components might have to be located in the direct neighbourhood of large thermal masses. Interactions between the large thermal capacity of the thermal masses and the relatively small solder deposits of the electrical components occur through this, and can lead to insufficient reflow of the solder during the soldering process. 
Figure 1 Design of the test device and layout of the thermal vias

Schematic of the test board

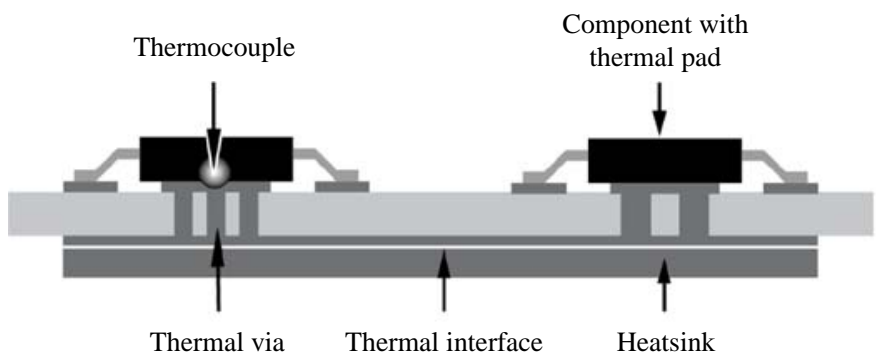

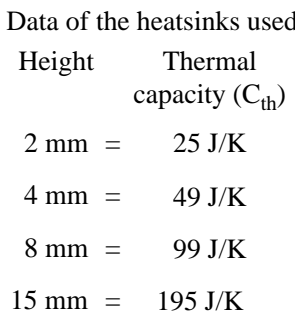

Layout of test board and the thermal vias

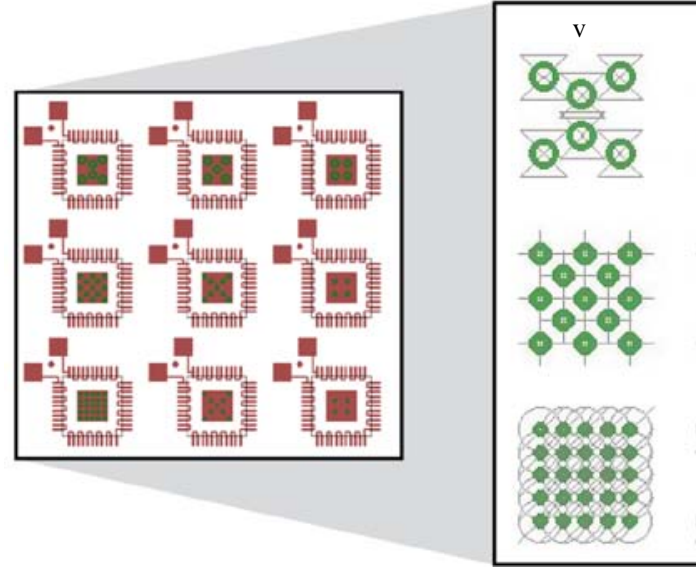

Figure 2 Influence of the thermal via layout on the gainable temperature in the solder joint

Differences in the peak temperature during soldering

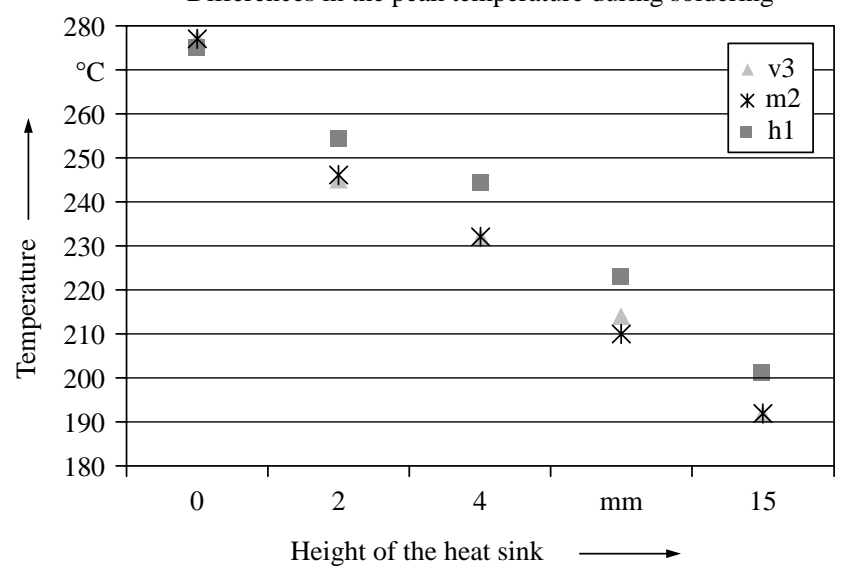

To investigate those thermal effects, a test board was designed, which is shown in Figure 3. On the PCB, four thermal masses made out of copper with specific thermal capacities can be placed. The capacities range between 38.5 and $192 \mathrm{~J} / \mathrm{K}$ and, for comparison, a test board with no thermal mass was used as well. Located around these thermal masses are electrical components of the kind CR 1206. The distance of the components from the copper blocks are 3, 6 and $9 \mathrm{~mm}$ to get an influence with respect to the distance. As can be seen in Figure 3, the components are additionally influenced by one, two or four thermal masses according to their location on the PCB. The three components on the upper right side of the layout can be used for metallurgical research. Five thermocouples were integrated on the PCB, but for this paper the investigation will be based only on two of them. Their location is shown in Figure 3 and they are identified as TC 1 and TC 2. According to that, TC 1 is under the influence of four thermal masses and TC 2 is located between two thermal masses but on the border of the test board.

For a more detailed characterisation of the heat deposition on the test board, a simulation of the PCB has been conducted in addition to the real-time measurement of the soldering profiles under the influence of the different thermal masses. The results are shown in Figure 4 for the two locations of the thermocouples. The two graphs shown in Figure 4 compare the measured and simulated temperatures for TC 1 and TC 2 for the thermal capacities "none" and " 25 ", which are the two extreme values. Even for the measuring point located at the border of the test board (TC 2) a significant decrease in the peak temperature of $25 \mathrm{~K}$ during soldering can be seen, which means, on the basis of a soldering profile according to IPC/JEDEC J-STD-020, that the temperature reaches the liquidus temperature of the solder alloy at the most. But even for the thermal masses with a lower thermal capacity (" 05 " and " 15 "), a clear reduction of the peak temperature of $8 \mathrm{~K}$, respectively, $18 \mathrm{~K}$ can be detected. These characteristics become even more explicit if the components are under the influence of more thermal 
Figure 3 Design of the test device

Schematic and layout of the testboard
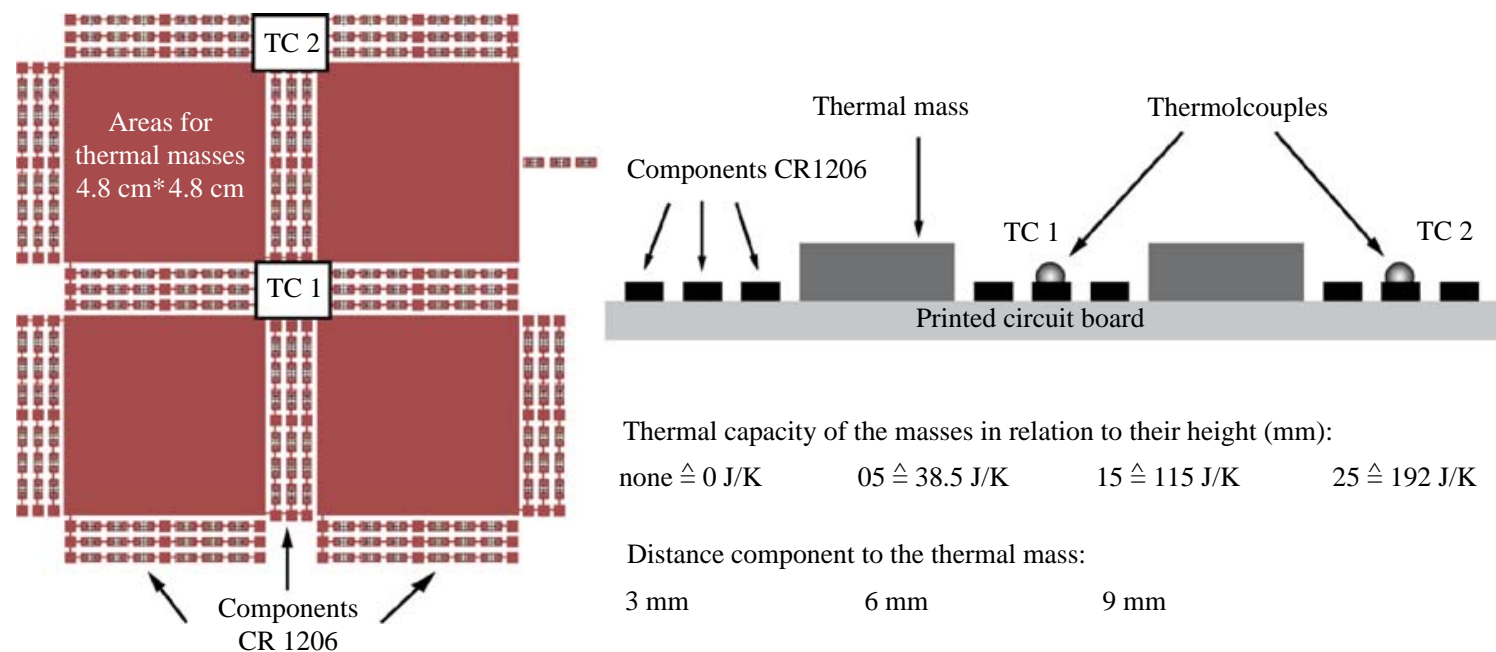

Thermal capacity of the masses in relation to their height $(\mathrm{mm})$ :

none $\triangleq 0 \mathrm{~J} / \mathrm{K} \quad 05 \hat{=} 38.5 \mathrm{~J} / \mathrm{K} \quad 15 \hat{=} 115 \mathrm{~J} / \mathrm{K} \quad 25 \hat{=} 192 \mathrm{~J} / \mathrm{K}$

Distance component to the thermal mass:

$\begin{array}{lll}3 \mathrm{~mm} & 6 \mathrm{~mm} & 9 \mathrm{~mm}\end{array}$

Figure 4 Influences on the soldering profile

Influence of thermal masses on the soldering profile
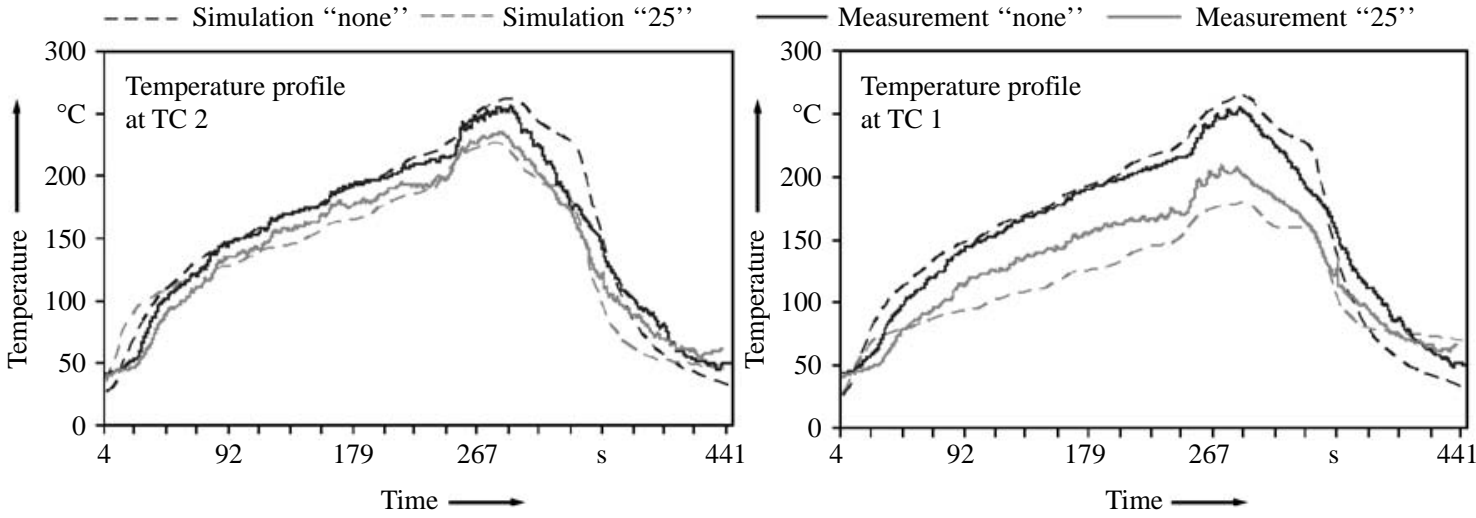

$\Delta \mathrm{T}$ to initial temperature with no thermal mass

\begin{tabular}{r|l|l|l} 
Thermal mass & 05 & 15 & 25 \\
\hline TC 1 & $13 \mathrm{~K}$ & $30 \mathrm{~K}$ & $25 \mathrm{~K}$ \\
\hline TC 2 & $8 \mathrm{~K}$ & $18 \mathrm{~K}$ & $25 \mathrm{~K}$
\end{tabular}

Simulation of the flow rate on the pcb

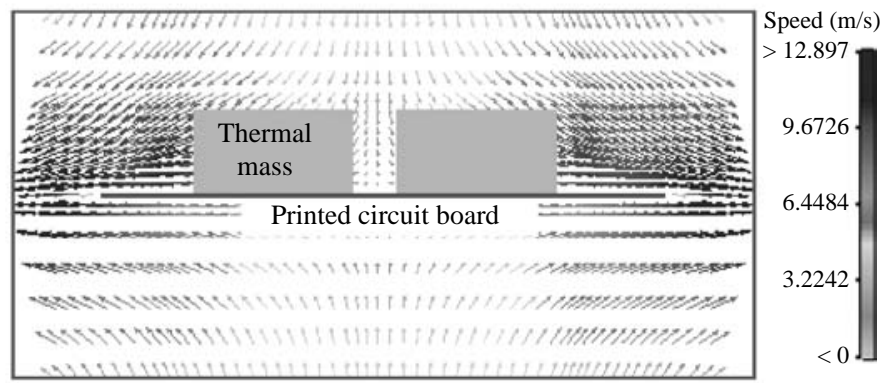

mass. For the measuring point TC 1 , the decrease in the peak temperature range is between $13 \mathrm{~K}$ for the thermal mass " 05 " and $45 \mathrm{~K}$ for the thermal mass 25 .

With the simulation model, the flow conditions on the PCB can be described according to the thermal mass (Figure 4). Thereby, it was shown that besides the mere thermal effect, the flow rate, which is highly influenced by the height of the thermal mass, might also have an effect on the measured temperatures. To investigate this effect, an additional test board was designed which is described in the next section.

Besides, the mere differences in the temperatures on the surface of the PCB, the influences of the thermal masses on the shear strength of the solder joints and its metallurgical formation are also of great importance. The reason for this is 
that from only the temperature point of view the solder should have been reflowed and looks like that on the surface in optical inspection. But the metallurgical formation might show defects inside the solder joint due to too less heat input. This again can lead to reduced shear strength and therefore reduced reliability of the interconnection. On this account, the shear strength of the components has been measured and, additionally, cross-section views of the components have been prepared.

The results of this investigation are shown in Figure 5. The diagram shows the shear strength of the CR 1206 components with respect to their location and distance to the thermal mass and their thermal capacity. As can be seen, a capacity of $115 \mathrm{~J} /$ $\mathrm{K}$ seems not to have an influence on the mechanical strength of the solder joint, independent from its location on the test board. Even the thermal masses " 15 " and " 25 " do not influence the shear strength of the components that are located in a distance of 6 and $9 \mathrm{~mm}$ from copper blocks. The shear strength is only reduced significantly if the electrical components are located in the direct neighbourhood of the thermal mass and are, respectively, located between two thermal masses (Figure 5). An adequate number of test boards were exposed to temperature-shock-cycling (parameters: $-40^{\circ} \mathrm{C} /+125^{\circ} \mathrm{C}$ ) and humidity tests (parameters: $+85^{\circ} \mathrm{C} / 85$ per cent relative humidity). During and after the tests the shear strength was measured, but no further influence of the thermal masses on the mechanical stiffness of the solder joints could be detected.

A cross-sectional view of a solder joint according to the thermal mass used can be seen in Figure 5. In its initial state, the solder shows a good wetting, but even under the influence of the thermal mass " 05 " a reduced meniscus can be seen. The meniscus is drastically reduced under the influence of thermal mass "15", but shows a surface as if the solder has been reflowed. If the magnification is increased "not reflowed" areas in the solder joint become visible, which indicates that the thermal input was not enough. For the thermal mass " 25 " no reflow process can be seen for the solder, leaving the paste in its initial state.

The discussed results show that due to the missing thermal connection from the solder joint to the thermal capacity, the influence is only significant if the thermal capacity is very high. This in return shows the possibilities of placing components even on the side of the PCB where a heat sink

Figure $\mathbf{5}$ Shear strength and metallurgical analysis

Shear strength of the solder joint in relation to its location to the thermal mass

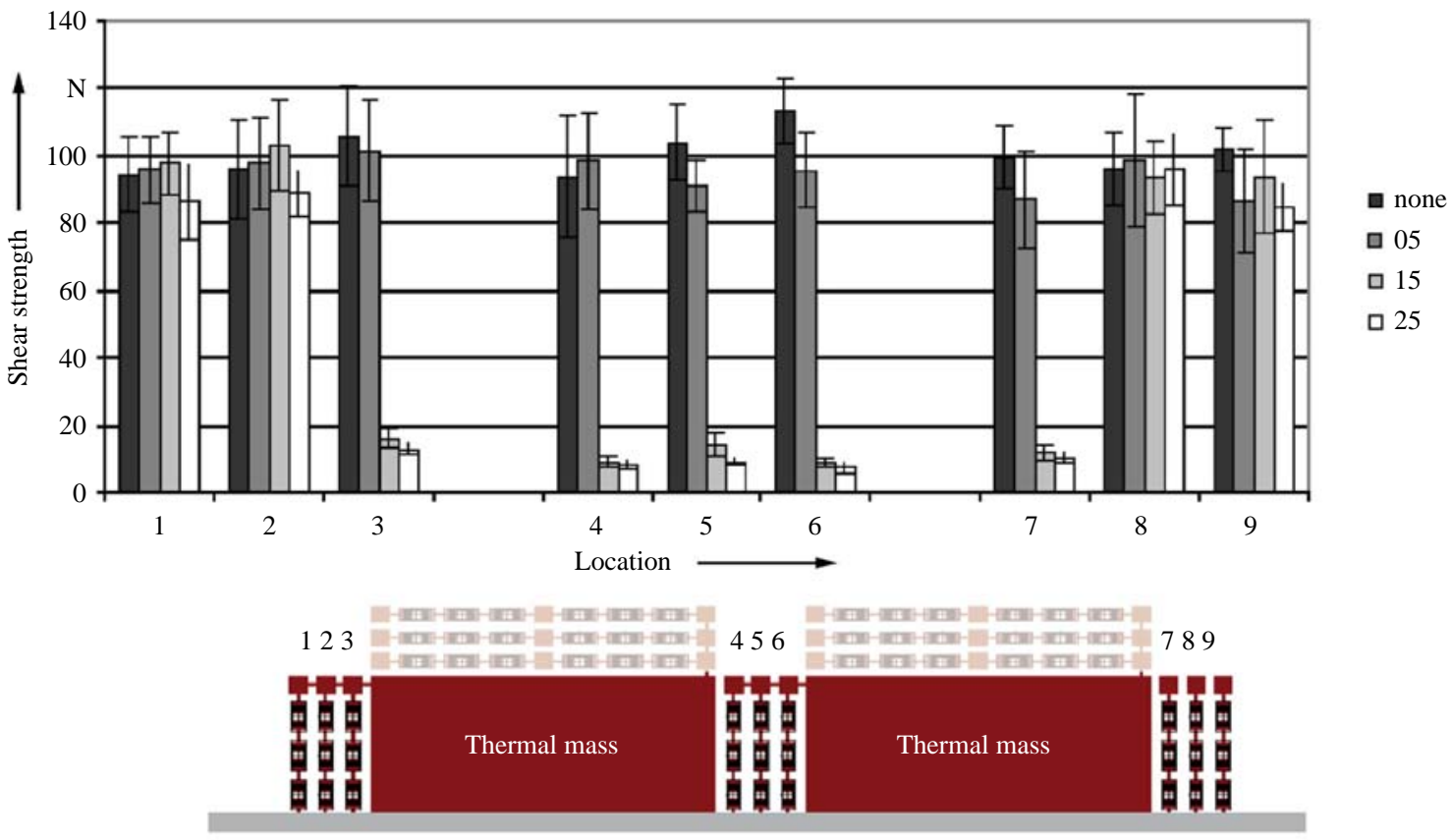

Metallografic analysis of the solder joint in relation to the thermal mass
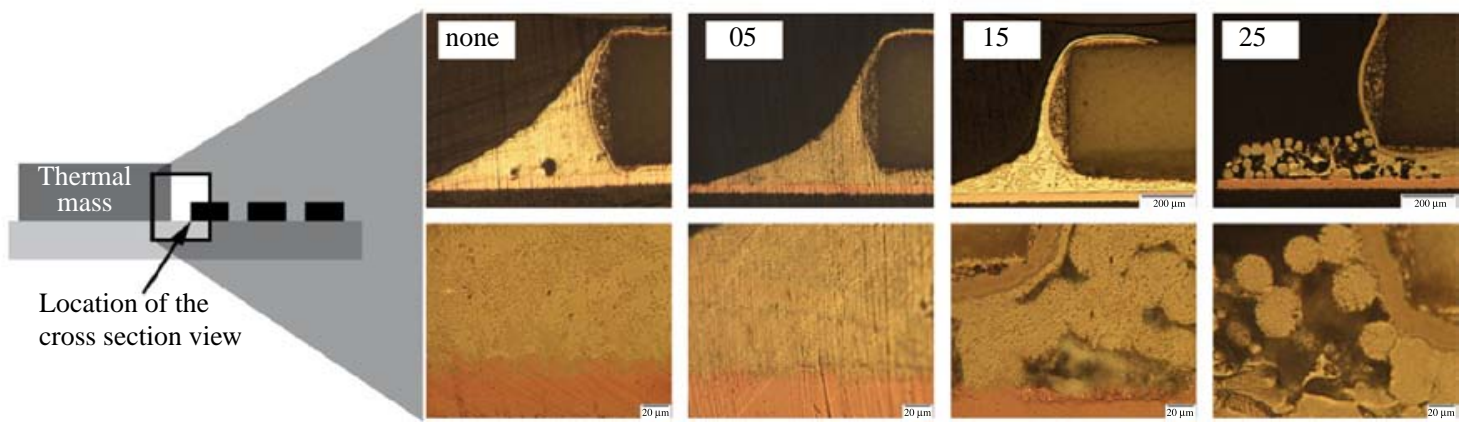
is located. This might give PCB-designers more freedom in designing electronic devices, even if thermal management has to be integrated into the PCB.

\section{Shadowing effects on PCBs}

As already mentioned, one result of the simulation from the section above was, that besides thermal effects, shadowing effects might also have an influence on the temperature deposition on a PCB. The influence of shadowing effects was a big challenge when IR was used as a heat source in soldering ovens, but could be reduced to a minimum with the invention of forced connection and vapour phase soldering. Nevertheless, on the basis of the results from the simulation, a test board was designed to get information on whether shadowing effects still have to be considered during soldering.

The schematic of the test device is shown in Figure 6. The spectrum of components includes passive components of the size CR 0603, CR 0402 and CR 0201 as well as ball grid arrays - BGAs (pitch: $1.0 \mathrm{~mm}$ ) and Chip Sale Packages (pitch: $0.5 \mathrm{~mm}$ ). Also, a structure to investigate the wetting of the solder was included. The black lines in Figure 6 represent shielding plates of different heights with which shadowing effects of different kind can be provoked. Besides, the height of the plates, the flow rate in the soldering oven was varied. The optical inspection was supported by measuring the temperature profiles at specific locations indicated with TC 1 to TC 5 in Figure 7.

From the results, it can be clearly seen that the shadowing effects of the shielding plates have no optically detectable influence on the wetting behaviour of the passive components and on the wetting test structures on the PCB for 100 per cent heating power. Even in the corners of the shielding plates, where the flow rate should be considerably decreased (positions 1 and 3 in Figure 6), good wetting of the solder on the metallization and the component can be seen. The lands for the BGA were designed with a tear drop design to detect bad wetting caused by a too low heat input. But the tear drop designs could be clearly seen in X-ray

Figure 6 Influence of shadowing effects on printed circuit boards

Schematic of the testboard and parameters used

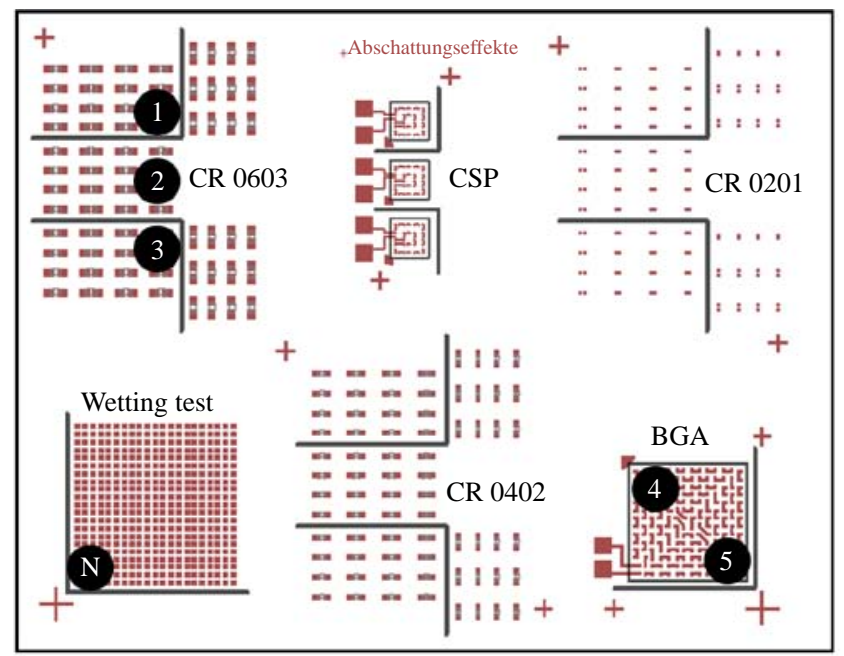

\section{Shielding plates}

Height of the shielding plates:

none

$5 \mathrm{~mm}$

$10 \mathrm{~mm}$

$15 \mathrm{~mm}$

Flow rate in the soldering oven:

$13 \mathrm{~m} / \mathrm{s}$ (100\% heating power)

$9 \mathrm{~m} / \mathrm{s} \quad$ (70\% heating power)

$6 \mathrm{~m} / \mathrm{s} \quad$ (50\% heating power)

Five thermocouples

$1=\mathrm{TC} 1 \ldots 5=\mathrm{TC} 5$

Solder wetting at position $1-0 \mathrm{~mm} / 25 \mathrm{~mm}$ shielding plate (100\% heating power)

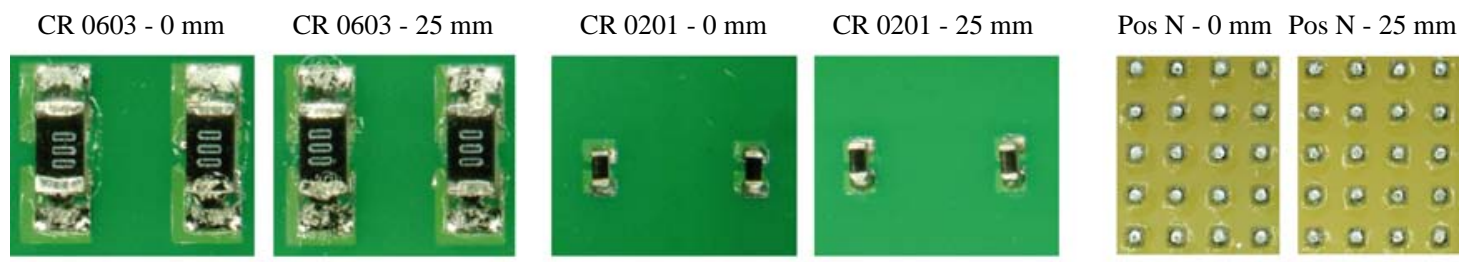

Influence on time over liquidus - $\Delta \mathrm{t}$ for none and $25 \mathrm{~mm}$ shielding plate

\begin{tabular}{|l|c|c|c|c|c|}
\cline { 2 - 7 } \multicolumn{1}{c|}{} & \multicolumn{5}{c|}{ Position } \\
\hline Flow rate & TC 1 & TC 2 & TC 3 & TC 4 & TC 5 \\
\hline $13 \mathrm{~m} / \mathrm{s}$ & $2 \mathrm{~s}$ & $2 \mathrm{~s}$ & $-1 \mathrm{~s}$ & $-2 \mathrm{~s}$ & $1 \mathrm{~s}$ \\
\hline $9 \mathrm{~m} / \mathrm{s}$ & $3 \mathrm{~s}$ & $-2 \mathrm{~s}$ & $-1 \mathrm{~s}$ & $-1 \mathrm{~s}$ & $-3 \mathrm{~s}$ \\
\hline $6 \mathrm{~m} / \mathrm{s}$ & $6 \mathrm{~s}$ & $-7 \mathrm{~s}$ & $-8 \mathrm{~s}$ & $-8 \mathrm{~s}$ & $-10 \mathrm{~s}$ \\
\hline
\end{tabular}


Figure 7 Measured surface temperatures on varying substrate geometries
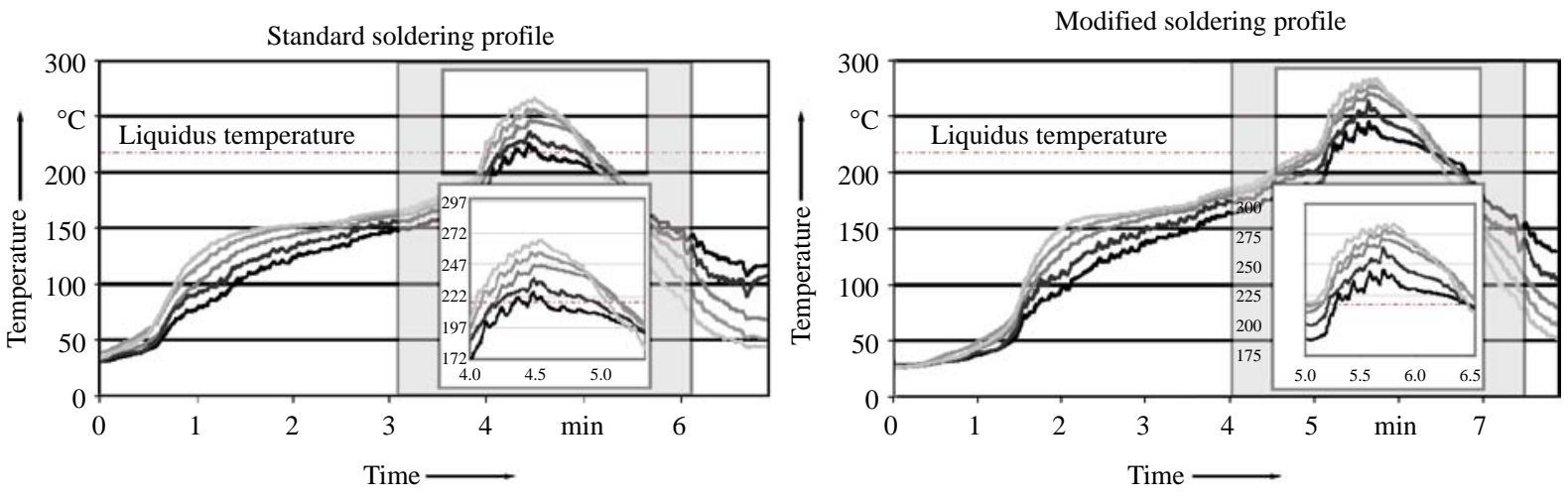

- FR 4 - PA6T/6I ribbed - PPS ribbed - PA6T/6I 2D - PPS 2D

\begin{tabular}{|c|c|c|c|c|c|}
\cline { 2 - 5 } \multicolumn{1}{c|}{} & \multicolumn{4}{c|}{ Substrate material and geometry } \\
\hline $\begin{array}{c}\text { Peak } \\
\text { temperature }\end{array}$ & $\begin{array}{c}\text { FR } 4 \\
\text { reference }\end{array}$ & $\begin{array}{c}\text { PA6T/6I } \\
\text { ribbed }\end{array}$ & $\begin{array}{c}\text { PPS } \\
\text { ribbed }\end{array}$ & $\begin{array}{c}\text { PA6T/6I } \\
2 \mathrm{D}\end{array}$ & $\begin{array}{c}\text { PPS } \\
2 \mathrm{D}\end{array}$ \\
\hline Standard (peak) & $246^{\circ} \mathrm{C}$ & $226^{\circ} \mathrm{C}$ & $236^{\circ} \mathrm{C}$ & $256^{\circ} \mathrm{C}$ & $266^{\circ} \mathrm{C}$ \\
\hline Modified (peak) & $272{ }^{\circ} \mathrm{C}$ & $245^{\circ} \mathrm{C}$ & $264^{\circ} \mathrm{C}$ & $278^{\circ} \mathrm{C}$ & $283^{\circ} \mathrm{C}$ \\
\hline $\begin{array}{c}\text { Ration of peak } \\
\text { temperature }\end{array}$ & $\begin{array}{c}\text { PPS/PA6T/6I } \\
\text { ribbed }\end{array}$ & $\begin{array}{c}\text { PPS/PA6T/6I } \\
2 \mathrm{D}\end{array}$ & \multicolumn{2}{|c|}{ Ribbed } \\
\hline Standard (peak) & 1.05 & 1.04 & 1.02 \\
\hline Modified (peak) & 1.08 & 1.06 & \\
\hline Weight ratio & 1.07 & &
\end{tabular}

inspection, even for shielding plates of $25 \mathrm{~mm}$ height. An influence of the shadowing effect can be measured for the time over liquidus for the five thermocouples. But the process window for soldering (time over liquidus) is only significantly reduced for very low flow rates of the process gas in the reflow soldering oven. In this case, a counter measure could be an increase of the temperature in the zones of the soldering oven, but with the negative effect of a too high thermal input on components or the PCB itself.

\section{Substrate materials with specific thermal properties}

Epoxy-based FR 4 is still the standard substrate material for PCBs but with MIDs becoming more and more popular, specific challenges have to be met during soldering apart from the occasionally lower thermal stability of the thermoplastics. Owing to the fact that with MIDs usually the housing of an electronic device is the PCB at the same time, the mass that has to be heated up during soldering can be much higher, although the thermal conductivity of thermoplastics and FR 4 is quite similar. This is dramatically increased with the use of thermally conductive thermoplastics that can be used for an integrated thermal management (Amesöder et al., 2008). Hereby, the thermal mass of the PCB is increased significantly. In addition with the better thermal conductivity the temperatures in the zones of the soldering oven have to be considerably enhanced to securely reach the defined time over liquidus on the surface of the PCBs. The maximum temperatures in the soldering oven are limited due to two factors: the first one is a technological factor concerning the maximum temperature given by the machine manufacturer, which is typically between 300 and $320^{\circ} \mathrm{C}$. The other challenge is to prevent the components on the PCBs and the substrate material itself from overheating.

To evaluate the needs for a modification of the soldering profile when using thermoplastics as substrate materials, two different geometries with three different materials were investigated during reflow soldering. The first geometry is a ribbed PCB made of the high-temperature thermoplastics PA6T/6I and polyphenylene sulphide (PPS). The other geometry is a standard plate made of FR 4, PA6T/6I and PPS (Figure 7). The circuitry for the two geometries was the same.

The standard soldering profile designed for the FR 4 board is shown in Figure 7 (top left side) and the peak temperatures reached during soldering are given in the table of Figure 7 (bottom). It can be seen that for FR 4 (weight: $7.6 \mathrm{~g}$ ) the peak temperature is $246^{\circ} \mathrm{C}$, but for the ribbed substrate geometry only $226^{\circ} \mathrm{C}$ (weight PA6T/6I: $25.8 \mathrm{~g}$ ), respectively, $236^{\circ} \mathrm{C}$ (weight PPS: $24.2 \mathrm{~g}$ ) are reached. For the two-dimensional substrate made of thermoplastic material even higher temperatures were reached during soldering. In the next step, the soldering profile was adjusted for the ribbed 
geometry. The modified soldering profile and peak temperatures are given in Figure 7, too. Again it can be seen that the peak temperatures vary between the two thermoplastic materials. If the ratio of the peak temperatures for PPS and PA6T/6I is taken for the standard and the modified profile you get a value of 1.05, respectively, 1.07 for the ribbed geometry. This again is nearly the value of 1.07 for the ratio of the heavier (PA6T/6I) to the more lightly (PPS) thermoplastic. This indicates that a direct connection exists between the density, and therefore the thermal capacity, of substrate materials and the peak temperatures during forced convection soldering for a given substrate geometry. Furthermore, it has to be mentioned that with the ribbed geometry the soldering oven used for these experiments reached its technological limits, since the temperatures in the soldering zones could not be increased. With an even higher mass of the substrates, a secure soldering process might not have been possible.

\section{Conclusion}

The increased level of integration of electronic devices and the advanced thermal requirements at the installation space require the use of thermal management on PCBs. Hereby, components with specific thermal properties and with none, respectively, with a thermally connection to the electrical components on the PCB are brought into the process chain of electronics production. The soldering process is especially influenced by components from the thermal management, because they store a considerable amount of the heat energy provided in the soldering oven. A counter measure to secure the needed heat input for the reflow process of the solder is to increase the temperature in the soldering process. This again can lead to overheating of the occasionally thermally critical electronic components or to damage the PCB itself because of delamination.

Against this background, different test boards were designed to investigate the influence of components with specific thermal properties on the soldering process. Besides, the effects of components that are thermally connected to the solder joint, the effects of thermal masses in the direct- neighbourhood of electrical components were investigated. Additionally, research was done on the influence of the shadowing effect on PCBs that can be induced by electromagnetic stability shielding plates or large components. Even the use of thermoplastics as substrate materials can influence the soldering process significantly due to their higher thermal capacity, respectively, the mass going along with the PCB used as circuit carrier and housing of the electronic device. It is essential to all results that were gathered during the investigation that there are measurable influences on the soldering process by components with specific thermal properties. Nevertheless, those effects can be reduced by an increase in the temperatures in the soldering oven. Thereby, the effect of course, strongly depends on the fact of a thermal connection between the thermal mass and the solder joint. By increasing the temperature in the soldering oven to secure the reflow of the solder paste and therefore wetting on the metallization and components on the PCB, the risk of a local overheating or delamination of the PCB is imminent.

\section{References}

Amesöder, S., Ranft, F., Brocka, Z., Hörber, J. and Feldmann, K. (2008), "Potential for practical use of thermal conductive polymers improving soldering stability in 3D-MID", paper presented at the 8th International Congress Molded Interconnect Devices - Conference Proceedings, 3-D MID e.V., Fuerth.

Bailey, C. (2008), "Thermal management technologies for electronic packaging: current capabilities and future challenges for modelling tools", 10th Electronics Packaging Technology Conference Proceedings, IEEE, pp. 527-32.

Feldmann, K. (Ed.) (2008), Montage in der Leistungselektronik für globale Märkte - Design, Konzepte, Strategien, Springer, Berlin.

Ohadi, M. and Qi, J. (2004), "Thermal Management of Harsh-Environment Electronics", 20th IEEE SEMITHERM Symposium, IEEE.

Schußler, F., Rosch, M., Horber, J. and Feldmann, K. (2008), "Reliability aspects for electronic devices for advanced requirements", Circuit World, Vol. 34 No. 3, pp. 23-30.

Sergent, J.E. and Krum, A. (1998), Thermal Management Handbook for Electronics Assemblies, McGraw-Hill, New York, NY.

\section{About the authors}

Florian Schüßler studied Production Engineering at the University of Erlangen-Nuremberg. Since 2004, he worked as a scientific assistant at the Institute for Manufacturing Automation and Production Systems (FAPS), which was led by Professor Feldmann until February 2009. The Head of this Institution is now Professor Franke. His PhD thesis deals with the subjects of highly miniaturized and highly stressed electronic devices, as well as the use of thermoplastics as flexible and rigid substrate materials. Florian Schüßler is the corresponding author and can be contacted at: florian. schuessler@faps.uni-erlangen.de

Denis Kozic studied Electronic Engineering at the University of Erlangen-Nuremberg. Since 1996, he worked as a research engineer at the Institute for Manufacturing Automation and Production Systems (FAPS). His current fields of research deal with the reliability of electronic devices.

Jörg Franke studied Production Engineering at the University of Erlangen-Nuremberg. He earned his doctorate at the Institute of Professor Feldmann on his scientific research into the development of production technologies of 3D Molded Interconnect Devices. After some years of working as an international management consultant and as a business manager, he became Head of FAPS at the University of Erlangen in 2009. 